\title{
Correlates of Health Behavior among School-based Employees
}

\author{
By Wynn Gillan* \\ Millie Naquin ${ }^{\dagger}$ \\ Marie Zannis \\ Ashley Bowers ${ }^{+}$ \\ Julie Brewer \\ Sarah Russell
}

Employee health promotion programs increase work productivity and effectively reduce employer costs related to health care and absenteeism, and enhance worker productivity. Components of an effective worksite health program include stress management, exercise and nutrition and/or weight management classes or counseling. Few studies have documented correlates of health behaviors in school-based employees. A multi-component survey was used to examine relationships among stress, physical activity and specific food choices among employees in a southeastern Louisiana school district. Significant differences were found in coping styles by gender and employee status. Findings also indicated that employees who selected healthful foods were more likely to use taskoriented coping, considered an effective coping style. Further those employees who engaged in vigorous physical activity on a regular basis reported less perceived stress as well as more effective coping strategies. Since these behaviors appear to be interrelated, those conducting health promotion programs may consider a multidimensional approach when planning programs for employees. Intervention studies in a school-based population are needed to examine specific effects of different coping styles and healthy behaviors on employee productivity. Keywords: coping, worksite health promotion

\footnotetext{
* Southeastern Louisiana University, USA.

†Southeastern Louisiana University, USA.

${ }^{\ddagger}$ Southeastern Louisiana University, USA.

${ }^{+}$Southeastern Louisiana University, USA.

- Southeastern Louisiana University, USA.

Southeastern Louisiana University, USA.
} 


\section{Introduction}

Given the current economic conditions, inclusion of health promotion programs is becoming a more important $\mathrm{c}$ omponent of worksite health. The Centers for Disease Control and Prevention report that employers, on average, spend $\$ 1,685$ per employee per year for lost productivity costs related to health conditions or $\$ 225.8$ billion in the U.S. annually (Stewart, Ricci, Chee, \& Morganstein, 2003). Research further indicates that health promotion programs at worksites can result in a $25 \%$ reduction in costs associated with absenteeism, health care and disability workers' compensation (Carnethon et al., 2009; Chapman, 2005). Such programs are among the most useful non-medical strategies to improve and maintain the health of employees while controlling health care costs (Louis, Schultz, McDonald, Champagne, \& Edington, 2006). Worksite health programs have also been found to improve dietary and physical activity behaviors (Anderson et al., 2009) both of which are imperative to employees' health.

Worksite health promotion programs in school settings are among the eight interrelated components of the Coordinated School Health Program, as recognized by the Centers for Disease Control and Prevention (Allensworth \& Kolbe, 1987). Under this component, teachers and non-teaching staff have the opportunity to participate in health assessments, education and health-related fitness activities. According to the School Health Policies and Programs Study 2006, about two-thirds of states provided support to school districts for activities and services that promote healthy lifestyles in faculty and staff (Eaton, Marx, \& Bowie, 2007). In addition, Healthy People 2020 maintains the need to provide comprehensive health promotion programs at the worksite (U.S. Department of Health and Human Services [USDHHS], 2010). As noted in Healthy People 2020 several components of an effective worksite health program include stress management, employer- based exercise facilities, and nutrition/weight management classes or counseling.

Many school-based worksite programs include stress management strategies for staff. Stress is an inevitable part of a school employee's life (Stern \& Cutler, 2002) and the physiological response may lead to teacher attrition, absenteeism and other disorders such as anxiety and depression (Austin, Shah, \& Muncher, 2005; Hammond \& Onikama, 1997). As such, its effects can be costly to the employer. Programs that help employees manage their stress have been shown to reduce anxiety, fatigue, depression and teacher burnout (Anderson, Levinson, Barker, \& Kiewra, 1999). In a study of teachers, it was found that allowing employees to identify their own levels of stress assisted them in devising a personalized intervention program (Gold, 1987).

Healthy People 2020 reports that physical activity is among the leading indicators for sound health (USDHHS, 2010). In turn, physical activity builds resilience to stress and provides long-term effects in preventing future stress episodes (Nagel \& Brown, 2003). Teachers who engage in both competitive and noncompetitive forms of physical activity are found to have lower levels of 
stress than their higher-stressed counterparts (Austin et al., 2005). Furthermore, physical activity reduces the physical indicators of stress including inflammatory markers (Pedersen \& Hoffman-Goetz, 2000). For instance, those who engage in physical activities often experience a reduction in their risk for high blood pressure, high cholesterol (Thompson et al., 2007), diabetes, cancer (Bernstein, Henderson, Hanisch, Sullivan-Halley, \& Ross, 1994; Peters et al., 2009), anxiety disorders (Mather et al., 2002), and depression (Blumenthal et al., 1999). Also, it has been found that individuals with higher self-efficacy are more likely to engage in physical activity (Kaewthummanukul \& Brown, 2006).

Worksite programs have also addressed the area of healthful eating, particularly increasing nutrient dense foods and reducing the intake of sugary ones. In the past two decades, sugared beverage consumption has increased substantially (Bleich, Wang, Wang, \& Gortmaker, 2009; Kant \& Graubard, 2006; Putnam \& Allshouse, 1999) and mirrors increased rates of many chronic conditions. Cohort studies have linked sweetened soft drinks with obesity (Woodward-Lopez, Kao, \& Ritchie, 2010), type 2 diabetes (Schulze et al., 2004), and components of the metabolic syndrome (Dhingra et al., 2007; Yoo et al., 2004). Certain types of sodas are associated with reduced bone mineral density (Tucker et al., 2006), calcium excretion (Heaney \& Rafferty, 2001), gout (Choi \& Curhan, 2008; Winkelmayer, Stampfer, Willett, \& Curhan, 2005), and pancreatic cancer (Larsson, Bergkvist, \& Wolk, 2006). High consumption of sugared beverages may also reduce intakes of more nutrient rich foods, adversely affecting health (Howard \& Wylie-Rosett, 2002).

Worksite stress may contribute to increased consumption of snack foods and sweets (Payne, Jones, \& Harris, 2005). Consumption of sweet energy dense foods (high in refined sugar and fat) is associated with higher levels of perceived stress (Oliver, Wardle, \& Gibson, 2000). Further, individuals who are emotionally upset tend to choose more energy dense foods than those who are non- emotional eaters (Garg, Wansink, \& Inman, 2007; Wainer, 2010; Zellner et al., 2006). One study found that teachers who exhibited high organizational climate scores (favorable relationship with co- workers and administrators) reported higher fruit and juice intake than did teachers with lower organizational climate (Cullen et al., 1999). Another study examined job strain and its relationship to healthy eating and participation in exercise. Those who perceived higher job strain were more likely to eat energy dense foods, although there was no relationship between job strain and exercise behaviors (Payne et al., 2005).

Some studies have looked at the relationship between food consumption and stress. Fewer studies have examined the relationships among stress, physical activity and nutritional intake among school employees at the worksite. This study sought to determine associations among stress, physical activity, and specific food choices among employees in a southeastern Louisiana school district. 


\section{Methods}

A convenience sample of employees who were eligible for participation in a rural southeastern Louisiana school board health promotion program (high school faculty and staff, employees of the school district and school board members) were sent an online questionnaire by email. Faculty and staff who did not respond after two or four weeks were sent a follow-up email with a survey link. Incentives were offered to faculty and staff members during all three waves of emails. After a random drawing, incentives of four $\$ 25.00$ gift certificates to office supply stores were presented to participants.

Questions consisted of demographic information, stress, physical activity and nutrition items. We used two instruments to measure perceived stress, the Coping Inventory for Stressful Situations (CISS) (Endler \& Parker, 1990) and the Perceived Stress Scale (PSS) (Cohen, Kamarck, \& Mermelstein, 1983). Individuals were also asked certain items regarding physical activity from the NHANES (2007-2008) survey (Centers for Disease Control \& Prevention [CDC], 2000) and selected beverage and dietary questions from the Nurses' Health Study (2009).

All items related to demographics, stress, physical activity, and nutrition were added into an electronic survey via SurveyMonkey®. A team of experts in worksite health (academicians, practitioners, and content specialists) ensured content and face validity by completing the online survey and making suggestions to clarify content, except for questions from a standardized instrument. In turn, six teachers not participating in the study took the survey and provided an estimated completion time of 15 minutes with additional suggestions for rewording of items. Estimated completion time was provided to survey participants.

\section{Instruments and Survey Items}

The Perceived Stress Scale (PSS), developed by Cohen, et al. (1983), measures perception of stress, specifically the degree to which individuals appraise situations in life as being stressful by being unpredictable, uncontrollable and overloaded. This 14-item scale asks about feelings and thoughts during the past month. Participants were asked how often they felt a certain way. A sample item was, "In the last month, how often have you been upset because of something that happened to you unexpectedly?" Likert-type scale responses included the following: never, almost never, sometimes, fairly often and very often.

The level of readability for the PSS is that of a junior high school reading level. To calculate a total level of perceived stress, seven items are reverse scored and then all are summed. Higher scores indicate higher levels of perceived stress. Previously determined alpha coefficients of reliability for this instrument were .84, .85, and .86 (Cohen et al., 1983). 
The second stress instrument used in this study was the Coping Inventory for Stressful Situations (CISS) (Endler \& Parker, 1990) which has 48 items. The three main subscales of the CISS include task-oriented, emotion-oriented and avoidance coping with each having 16 items and a possible range of scores from 16-80. Task- oriented coping is directed toward problem solving which includes cognitive restructuring and actions to change a situation. Emotion- oriented coping involves emotional reactions that are self-oriented such as self-blame, anger and becoming tense. Avoidance coping consists of activities or thoughts aimed at curtailing a stressful situation by escaping a situation such as engaging in social activities or performing non-problem related tasks. Avoidance coping is divided into two additional scales: distraction and social diversion. The distraction subscale contains eight items with a score range of 8-40; the social diversion subscale has five items with a range of 5-25.

For each item on the CISS, participants were asked to indicate how much they engaged in this activity when they encountered or experienced a difficult, stressful or upsetting situation. Sample items included: "Feel anxious about not being able to cope"; "Focus on the problem and see how I can solve it"; and "See a movie." Likert scale responses ranged from 1-5 with $1=$ not at all to $5=$ very much.

Physical activity questions were adapted from the National Health and Nutrition Examination Survey (NHANES) instrument ((CDC) \& (NCHS), 2000). Participants were provided examples of moderate activities such as brisk walking, vacuuming, or anything causing an increase in breathing or heart rate. They were then asked how many days they engaged in those activities for at least 10 minutes at a time. In addition to the number of days, participants were asked how much time (in minutes) they spent engaging in those activities. Similar questions were posed regarding vigorous exercise. Examples of vigorous exercise included running, aerobics, or anything that caused large increases in breathing or heart rate. Participants selected how many days they engaged in vigorous activities and the duration of those activities.

Beverage intake was measured using selected questions from the Nurses' Health Survey (2009) food frequency questionnaire. Participants were asked how often they consumed selected food and drinks. Responses included: (a) never, (b) 1-3 times per month, (c) 1 time per week, (d) 2-4 times per week, (e) 5-6 times per week, (f) 1 time per day, (g) 2-3 times per day, (h) 4-5 times per day, and (i) 6 or more times per day. For purposes of analyses, the previous response options were collapsed into five categories of the following: (a) never, (b) 1-3 times per month, $(c+d)$ 1-4 times per week, $(e+f)$ once a day, and $(\mathrm{g}+\mathrm{h}+\mathrm{i})$ more than once a day.

\section{Analyses}

Data were downloaded from SurveyMonkey® into Excel and then SPSS version 15 for analyses. Descriptive statistics were used and correlations were 
conducted to determine relationships among physical activity, stress and nutrition. Analysis of variance was used to determine differences among the three coping styles by gender and job status (teacher vs. non-teacher). Chisquare analyses were used to examine differences in exercise and nutritional behaviors by gender.

\section{Findings}

Of the 136 respondents $(\mathrm{N}=400$, for a $34 \%$ response rate), $71 \%$ were female, $81 \%$ were college graduates, and $24 \%$ had less than six years of work or teaching experience. Most respondents were teachers (60\%). Respondents' ages ranged from 23-67 years with a mean of $44.4(\mathrm{SD}=10.4)$. See Table 1 for additional demographics. Cronbach's Alpha (Table 2) was used to determine the reliability of the PSS and CISS scales along with the nutrition and physical activity questions.

Table 1. Demographic Characteristics

\begin{tabular}{|c|c|c|}
\hline & $\mathrm{n}$ & Percentage \\
\hline \multicolumn{3}{|l|}{ Gender } \\
\hline Male & 40 & 29 \\
\hline Female & 96 & 71 \\
\hline \multicolumn{3}{|l|}{ Education } \\
\hline High school & 12 & 9 \\
\hline Some college & 13 & 9 \\
\hline College grad & 69 & 51 \\
\hline Master + & 41 & 30 \\
\hline Other & 1 & 1 \\
\hline \multicolumn{3}{|l|}{ Position } \\
\hline Faculty & 81 & 60 \\
\hline Staff & 27 & 20 \\
\hline Administrator & 12 & 9 \\
\hline Retiree & 2 & 1 \\
\hline Board member & 3 & 2 \\
\hline Other & 11 & 8 \\
\hline \multicolumn{3}{|l|}{ Years taught/worked } \\
\hline $0-5$ & 32 & 24 \\
\hline $6-10$ & 19 & 14 \\
\hline $11-15$ & 22 & 16 \\
\hline $16-20$ & 14 & 10 \\
\hline $21-25$ & 15 & 11 \\
\hline $26-30$ & 16 & 12 \\
\hline $30+$ & 18 & 13 \\
\hline
\end{tabular}

Overall styles of coping with stress were determined by the use of the CISS. Task-oriented coping was used by most of the participants $(M=55.1)$, followed by avoidance coping $(M=45.2)$, and emotion-oriented coping $(M=$ 38.3 ), with no significant differences among their use, overall. However by gender, males had a significantly higher use of task-oriented coping ( $M=$ 58) than females $(M=53.9), \mathrm{F}=4.2, \mathrm{p}=.043$. In addition, teachers were 
more likely to use emotion-oriented coping $(\mathrm{M}=39.8)$ than non-teachers $(M=$ $36.2), \mathrm{F}=3.9, \mathrm{p}=0.05$.

Table 2. Cronbach's Alpha - Scales and Subscales

\begin{tabular}{|cccc|}
\hline Scale or Subscale & $\begin{array}{c}\text { Cronbach's } \\
\text { Alpha }\end{array}$ & $\begin{array}{c}\text { No. of } \\
\text { Items }\end{array}$ & $\begin{array}{c}\text { No. of } \\
\text { Subjects }\end{array}$ \\
\hline Perceived stress scale & .33 & 14 & 128 \\
Coping inventory & .87 & 48 & 122 \\
Task-oriented coping & .92 & 16 & 122 \\
Avoidance coping & .83 & 16 & 122 \\
Emotion-oriented coping & .89 & 16 & 122 \\
Nutrition - all items & .49 & 14 & 112 \\
Nutrition - beverage & .31 & 8 & 119 \\
Nutrition - vegetables & .72 & 5 & 113 \\
Physical activity & .55 & 7 & 62 \\
\hline
\end{tabular}

Among the respondents, $72 \%$ participated in moderate physical activities. Of those that participated in moderate activity, 66\% engaged 3-5 days/week for 26-60 minutes at a time. More than half of the participants $(56 \%)$ engaged in vigorous exercise, $70 \%$ of them for 3-5 days per week and $52.4 \%$ for 31-60 minutes. Males(71\%) were more likely to engage in vigorous activity than females $(52 \%), X^{2}(1)=3.3, p=0.05$. With regard to dietary intake, $61 \%$ reported eating fruit and $48 \%$ ate vegetables less than once a day (only 4 or fewer times per week). Pertaining to sleep, $37.8 \%$ reported getting 5-6 hours per night and $60.5 \%, 7-8$ hours.

\section{Relationships between Nutrition and Stress}

Regarding beverage consumption, over $40 \%$ of employees drank caffeinated coffee at least once a day. In addition, more than $32 \%$ drank a low calorie beverage containing caffeine at least every day. Fewer individuals $(22 \%)$ drank decaffeinated coffee at any time. Other reported beverage consumption is found in Table 3.

Table 3. Food and Beverage Frequency (\%)

\begin{tabular}{|c|c|c|c|c|c|}
\hline & Never & $1-3$ X month & $1-4$ days/wk & Once a day & $\begin{array}{c}2 \text { or } \\
\text { more/day }\end{array}$ \\
\hline $\begin{array}{c}\text { Low calorie } \\
\text { beverage with } \\
\text { caffeine }\end{array}$ & 35.8 & 18.3 & 13.3 & 18.3 & 14.2 \\
\hline $\begin{array}{c}\text { Low calorie } \\
\text { beverage } \\
\text { without caffeine }\end{array}$ & 49.2 & 18.3 & 14.2 & 15.0 & 3.3 \\
\hline $\begin{array}{c}\text { Carbonated } \\
\text { beverages with } \\
\text { caffeine and sugar }\end{array}$ & 48.3 & 20.0 & 15.8 & 9.2 & 6.7 \\
\hline $\begin{array}{c}\text { Other carbonated } \\
\text { beverages } \\
\text { with sugar }\end{array}$ & 62.5 & 19.2 & 10.8 & 6.7 & .8 \\
\hline
\end{tabular}




\begin{tabular}{|c|c|c|c|c|c|}
\hline $\begin{array}{c}\text { Herbal tea } \\
\text { without caffeine }\end{array}$ & 72.5 & 10.0 & 10.0 & 5.8 & 1.7 \\
\hline Tea with caffeine & 54.2 & 20.0 & 17.5 & 2.5 & 5.8 \\
\hline $\begin{array}{c}\text { Decaffeinated } \\
\text { coffee }\end{array}$ & 78.3 & 8.3 & 4.2 & 5.0 & 4.2 \\
\hline $\begin{array}{c}\text { Caffeinated } \\
\text { coffee }\end{array}$ & 38.3 & 6.7 & 11.7 & 21.7 & 21.7 \\
\hline Fruit juice & 14.3 & 33.6 & 29.4 & 17.6 & 5.0 \\
\hline Fruit not juice & 2.5 & 17.5 & 41.7 & 25.0 & 13.3 \\
\hline Green salad & 1.7 & 9.3 & 58.5 & 28.0 & 2.5 \\
\hline $\begin{array}{c}\text { Potatoes not } \\
\text { french fries or } \\
\text { potato chips }\end{array}$ & 8.3 & 20.0 & 65.0 & 5.8 & .8 \\
\hline $\begin{array}{c}\text { Carrots } \\
\text { Other vegetables }\end{array}$ & 16.1 & 32.2 & 40.7 & 10.2 & .8 \\
\hline
\end{tabular}

Relationships between beverage and food consumption revealed that drinking sugar sweetened soft drinks with caffeine was associated with a lower consumption of fruit. Decaffeinated coffee drinking was positively associated with green salad consumption. Green salad consumption increased the likelihood of selecting carrots and other vegetables. Those who chose "low calorie" beverages were less likely to drink herbal decaffeinated tea. Those selecting green salad and fruit were more likely to use task-oriented coping as a healthy way to control stress. Statistics regarding these correlations are found in Table 4.

Table 4. Correlations with Nutritional

\begin{tabular}{|c|c|c|c|c|}
\hline Items & $\mathrm{r}$ & significance & $\mathrm{n}$ & Power \% \\
\hline \multicolumn{5}{|l|}{ Low calorie beverage with caffeine } \\
\hline Low calorie beverage without caffeine & .29 & .00 & 120 & 90 \\
\hline \multicolumn{5}{|c|}{ Carbonated beverages with caffeine and sugar } \\
\hline Other carbonated beverages with sugar & .51 & .00 & 120 & 99 \\
\hline Fruit & -.21 & .02 & 120 & 94 \\
\hline Potato & .26 & .00 & 120 & 82 \\
\hline \multicolumn{5}{|l|}{ Decaffeinated coffee } \\
\hline Green salad & .21 & .03 & 118 & 63 \\
\hline \multicolumn{5}{|l|}{ Caffeinated coffee } \\
\hline Vegetables & .22 & .02 & 116 & 67 \\
\hline \multicolumn{5}{|l|}{ Fruit } \\
\hline Green salad & .49 & .00 & 118 & 99 \\
\hline Carrot & .28 & .00 & 118 & 87 \\
\hline Vegetables & .43 & .00 & 116 & 99 \\
\hline Task coping & .23 & .01 & 120 & 72 \\
\hline \multicolumn{5}{|l|}{ Green Salad } \\
\hline Carrot & .33 & .00 & 117 & 96 \\
\hline Vegetables & .56 & .00 & 114 & 99 \\
\hline Task coping & .27 & .00 & 118 & 85 \\
\hline Avoidance coping-social diversion & .20 & .05 & 118 & 59 \\
\hline
\end{tabular}




\section{Relationships among Stress, Physical Activity, and Nutritional Behaviors}

Correlations were performed to ascertain possible relationships among physical activity, nutritional intake, coping styles, and perceptions of stress. For example, those reporting more days of moderate exercise per week were more likely to consume decaffeinated coffee and green salad. These individuals were also less likely to engage in emotional-oriented coping. Further, those engaging in more minutes of moderate exercise per session were more likely to use task-oriented coping. Moreover, those who engaged in more days of vigorous exercise per week were less likely to report perceived stress or to use emotional-oriented coping. In addition, those engaging in more minutes of vigorous exercise per session were also less likely to consume diet decaffeinated beverages or potatoes. See Table 5 for more information.

Table 5. Correlations with Physical Activity

\begin{tabular}{|c|c|c|c|c|}
\hline Items & $\mathrm{r}$ & significance & $\mathrm{n}$ & Power $\%$ \\
\hline \multicolumn{5}{|c|}{ Days of moderate exercise } \\
\hline $\begin{array}{l}\text { Vigorous } \\
\text { minutes }\end{array}$ & .29 & .02 & 63 & 64 \\
\hline Vigorous days & .58 & .00 & 63 & 99 \\
\hline Decaf coffee & .24 & .02 & 96 & 66 \\
\hline Green salad & .21 & .05 & 94 & 53 \\
\hline $\begin{array}{l}\text { Emotional } \\
\text { coping }\end{array}$ & -.21 & .04 & 97 & 55 \\
\hline \multicolumn{5}{|c|}{ Minutes of moderate exercise } \\
\hline Vigorous days & .28 & .03 & 62 & 61 \\
\hline $\begin{array}{l}\text { Vigorous } \\
\text { minutes }\end{array}$ & .59 & .00 & 62 & 99 \\
\hline Task coping & .20 & .05 & 96 & 50 \\
\hline \multicolumn{5}{|c|}{ Days of vigorous exercise } \\
\hline PSS scale & -.29 & .02 & 66 & 67 \\
\hline $\begin{array}{l}\text { Emotional } \\
\text { coping }\end{array}$ & -.36 & .00 & 67 & 86 \\
\hline \multicolumn{5}{|c|}{ Minutes of vigorous exercise } \\
\hline $\begin{array}{c}\text { Low cal } \\
\text { beverage no } \\
\text { caffeine }\end{array}$ & -.26 & .04 & 66 & 57 \\
\hline Potato & -.27 & .03 & 66 & 60 \\
\hline
\end{tabular}

\section{Discussion}

Engaging in health-related behaviors such as, stress management, exercise and making healthy food selections appears to be interrelated. Healthy behaviors such as consuming green salads, vegetables, fruits and regular exercise correlated with other health-related behaviors such as selecting decaffeinated coffee and using task-oriented coping, a healthier coping style to control stress (Endler \& Parker, 1990). Conversely, those choosing sweetened soft drinks were less likely to select fruit. There exists concern about low 
consumption of nutrient dense foods which may increase the risk for a variety of chronic diseases (U.S. Department of Agriculture, 2010; Bleich et al., 2009). Increased intake of sweetened beverages is associated with obesity and diabetes and reducing soft drink consumption improves health status (Vartanian, Schwartz, \& Brownell, 2007). Worksite health promotion programs that educate about healthy eating, stress coping strategies and the selection of wise food choices may impact overall health and employee productivity.

In our study, those who exercised tended to make healthy food choices. Engaging in moderate levels of exercise may predict other healthy behaviors such as consuming decaffeinated coffee and green salads. In addition, moderate or vigorous exercise may lead to more health-oriented stress coping styles and less perceived stress, respectively. Those who exercised moderately to vigorously were less likely to engage in an emotional-oriented coping style, a less effective coping mechanism. Further, they were also less likely to report perceived stress. Having employees engage in even moderate exercise may help improve their resilience to stressful events and promote healthier coping styles. This may improve employee attendance and increase job performance.

Employees who make healthier lifestyle choices tend to use healthier stress management techniques, such as task-oriented coping. In this study, males were more likely to use task-orientedcoping than females. This may imply that the specific selection of stress management techniques would be important in helping female teachers and employees deal with perceived stress and environmental demands. However workplace strategies should be in place to help employees manage stress regardless of gender.

Of course, self selection bias may have influenced these results since those interested in health may also be more likely to participate in this study. These individuals may be more likely to participate and engage in a worksite health program and engage in health enhancing behaviors. It would be beneficial to confirm these results with a larger or more demographically varied sample.

\section{Conclusion}

Since health-related behaviors appear to be linked in our study, it may be helpful for those conducting school health promotion programs to consider a multi-dimensioned approach in educational programming endeavors. Selecting strategies that address stress management, nutritional intake and physical activity may impact the health of school employees by reducing absenteeism and health care costs while improving staff productivity. Employees may benefit from having healthier food choices at the worksite as they may be more likely to choose available healthier options. Providing more time for meals or other stress reducing strategies may promote more healthful behaviors. In addition, having onsite facilities and programs may increase the likelihood of employees participating in physical activity and 
stress management sessions while promoting their well-being. Finally, providing stress breaks and promoting skills to reduce perceived stress could result in happier, healthier employees and reduce health care costs for school systems.

\section{References}

Allensworth, D., \& Kolbe, L. (1987). The comprehensive school health program: Exploring an expanded concept. Journal of School Health, 57(10), 409-412. Anderson, L.M., Quinn, T.A., Glanz, K., Ramirez, G., Kahwati, L.C., Johnson, D.B.,. . . Katz, D.L. (2009). The effectiveness of worksite nutrition and physical activity interventions for controlling employee overweight and obesity: A systematic review. American Journal of Preventive Medicine, 37(4), 340-357.

Anderson, V., Levinson, E., Barker, W., \& Kiewra, K. (1999). The effects of meditation on teacher perceived occupational stress, state and trait anxiety, and burnout. School Psychology Quarterly, 14(1), 3-25.

Austin, V., Shah, S., \& Muncher, S. (2005). Teacher stress and coping strategies used to reduce stress. Occupational Therapy International, 12(2), 63-80.

Bernstein, L., Henderson, B., Hanisch, R., Sullivan-Halley, J., \& Ross, R. (1994). Physical exercise and reduced risk of breast cancer in young women. Journal of the National Cancer Institute, 86, 1403 -1408.

Bleich, S. N., Wang, Y. C., Wang, Y., \& Gortmaker, S. L. (2009).

Increasing consumption of sugar-sweetened beverages among US adults: 1988-1994 to 1999-2004. The American Journal of Clinical Nutrition, 89(1), 372-381.

Blumenthal, J. A., Babyak, M. A., Moore, K. A., Craighead, W. E., Herman, S., Khatri, P., . . . Krishnan, K. R. (1999). Effects of exercise training on older patients with major depression. Archives of Internal Medicine, 159(19), 23492356. doi: 10.1001/archinte.159.19.2349

Carnethon, M., Whitsel, L. P., Franklin, B. A., Kris-Etherton, P., Milani, R., Pratt, C. A., \& Wagner, G. R. (2009). Worksite wellness programs for cardiovascular disease prevention: A policy statement from the American Heart Association. Circulation, 120(17), 1725-1741. doi: 10.1161/circulationaha.109.192653

Centers for Disease Control \& Prevention (2000). National Health and Nutrition Examination Survey Questionnaire. Hyattsville, MD: U.S. Department of Health and Human Services.

Chapman, L. (2005). Healthier, happier, and more productive employees Retrieved August 14, 2012, from http://www.cdc.gov/dhdsp/pubs/docs/presentation 508.pdf

Choi, H. K., \& Curhan, G. (2008). Soft drinks, fructose consumption, and the risk of gout in men: Prospective cohort study. BMJ, 336(7639), 309-312. doi: 10.1136/bmj.39449.819271.BE

Cohen, S., Kamarck, T., \& Mermelstein, R. (1983). A global measure of perceived stress. Journal of Health and Social Behavior, 24, 386-396. Cullen, K. W., Baranowski, T., Baranowski, J., Hebert, D., deMoor, C., Hearn, M. D., \& Resnicow, K. (1999). Influence of school organizational characteristics on the outcomes of a school health promotion program. Journal of School Health, 69(9), 376-380.

Dhingra, R., Sullivan, L., Jacques, P. F., Wang, T. J., Fox, C. S., Meigs, 
J. B., . . . Vasan, R. S. (2007). Soft drink consumption and risk of developing cardiometabolic risk factors and the metabolic syndrome in middle-aged adults in the community. Circulation, 116(5), 480-488. doi: 10.1161/circulationa ha.107.689935

Eaton, D. K., Marx, E., \& Bowie, S. E. (2007). Faculty and staff health promotion: Results from the School Health Policies and Programs Study 2006. Journal of School Health, 77, 557-566.

Endler, N., \& Parker, J. (1990). Multidimentional assessment of coping: A critical evaluation. Journal of Personality and Social Psychology, 58(5), 844-854.

Garg, N., Wansink, B., \& Inman, J., J. (2007). The influence of incidental affect on consumers' food intake. Journal of Marketing, 71, 194-206. Gold, Y. (1987). Stress reduction programs to prevent teacher burnout. Education, 107(3), 338341.

Hammond, O. W., \& Onikama, D. L. (1997). At risk teachers. Retrieved from http://www.prel.org/products/Products/AtRisk-teacher.pdf Heaney, R. P., \& Rafferty, K. (2001). Carbonated beverages and urinary calcium excretion. American Journal of Clinical Nutrition, 74(3), 343- 347.

Howard, B. V., \& Wylie-Rosett, J. (2002). Sugar and cardiovascular disease: A statement for healthcare professionals from the committee on nutrition of the Council on Nutrition, Physical Activity, and Metabolism of the American Heart Association. Circulation, 106, 523- 527.

Kaewthummanukul, T., \& Brown, K. C. (2006). Determinants of employee participation in physical activity: Critical review of the literature. American Association of Occupational Health Nurses Journal, 54(6), 249-261.

Kant, A. K., \& Graubard, B. I. (2006). Secular trends in patterns of self- reported food consumption of adult Americans: NHANES 1971-1975 to NHANES 1999-2002. The American Journal of Clinical Nutrition, 84(5), 1215-1223.

Larsson, S. C., Bergkvist, L., \& Wolk, A. (2006). Consumption of sugar and sugarsweetened foods and the risk of pancreatic cancer in a prospective study. American Journal of Clinical Nutrition, 84(5), 1171-1176.

Louis, Y., Schultz, A. B., McDonald, T., Champagne, L., \& Edington, D.W. (2006). Participation in employer-sponsored wellness programs before and after retirement. American Journal of Health Behavior, 30, 27-38.

Mather, A. S., Rodriguez, C., Guthrie, M. F., McHarg, A. M., Reid, I. C., \& McMurdo, M. E. T. (2002). Effects of exercise on depressive symptoms in older adults with poorly responsive depressive disorder: Randomised controlled trial. The British Journal of Psychiatry, 180(5), 411-415. doi: 10.1192/bjp.180.5.411

Nagel, L., \& Brown, S. (2003). The ABCs of managing teacher stress. Clearing House, 76(5), 255-258.

Oliver, G., Wardle, J., \& Gibson, E. L. (2000). Stress and food choice: A laboratory study. Psychosomtic Medicine, 62(6), 853-865.

Payne, N., Jones, F., \& Harris, P. (2005). The impact of job strain on the predictive validity of the theory of planned behaviour: An investigation of exercise and healthy eating. British Journal of Health Psychology, 10(1), 115-131.

Pedersen, B. K., \& Hoffman-Goetz, L. (2000). Exercise and the immune system: Regulation, integration, and adaptation. Physiological Reviews, 80(3), 1055-1081.

Peters, T., Moore, S., Gierach, G., Wareham, N., Ekelund, U., Hollenbeck, A., . . . Leitzmann, M. (2009). Intensity and timing of physical activity in relation to postmenopausal breast cancer risk: The prospective NIH- AARP Diet and Health Study. BMC Cancer, 9(1), 349. 
Putnam, J., \& Allshouse, J. (1999). Food consumption, prices, and expenditures, 197097. USDA Statistical Bulletin No. 965. Retrieved from www.ers.usda.gov/publica tions/sb-statistical-bulletin/sb965.aspx/

Schulze, M. B., Manson, J. E., Ludwig, D. S., Colditz, G. A., Stampfer, M. J., Willett, W. C., \& Hu, F. B. (2004). Sugar-sweetened beverages, weight gain, and incidence of type 2 diabetes in young and middle- aged women. Journal of the American Medical Association, 292(8), 927-934. doi: 10.1001/jama.292.8.927

Stern, F., \& Cutler, S. (2002). Psychosocial occupational therapy: A holistic approach ( 2 ed.). San Diego: Singular Publishing.

Stewart, W., Ricci, J., Chee, E., \& Morganstein, D. (2003). Lost productive work time costs from health conditions in the United States: Results from the American productivity audit. Journal of Occupational \& Environmental Medicine, 45(12), 1234-1246.

Thompson, P. D., Franklin, B. A., Balady, G. J., Blair, S. N., Corrado, D., Estes, N. A. M., III, . . . Costa, F. (2007). Exercise and acute cardiovascular events: Placing the risks into perspective: A scientific statement from the American Heart Association Council on Nutrition, Physical Activity, and Metabolism and the Council on Clinical Cardiology. Circulation, 115(17), 2358-2368. doi: 10.1161/circulatio naha.107.181485

Tucker, K. L., Morita, K., Qiao, N., Hannan, M. T., Cupples, L. A., \& Kiel, D. P. (2006). Colas, but not other carbonated beverages, are associated with low bone mineral density in older women: The Framingham Osteoporosis Study. American Journal of Clinical Nutrition, 84(4), 936-942. 
